\title{
CORRELATION BETWEEN BARKHAUSEN NOISE AND COERCIVITY IN AMORPHOUS AND NANOCRYSTALLINE $\mathrm{Fe}-\mathrm{Cu}-\mathrm{Nb}-\mathrm{Si}-\mathrm{B}$ ALLOYS
}

\author{
L. MALKIŃSKI \\ Institute of Physics, Polish Academy of Sciences \\ Al. Lotników 32/46, 02-668 Warszawa, Poland \\ AND T. KULIK \\ Department of Materials Science and Engineering, Warsaw University of Technology \\ Narbutta 85, 02-524 Warszawa, Poland
}

\begin{abstract}
Samples of amorphous and nanocrystalline alloys were prepared by proper annealing of the metallic glasses: $\mathrm{Fe}_{73.5} \mathrm{Cu}_{1} \mathrm{Nb}_{3} \mathrm{Si}_{13.5} \mathrm{~B}_{9}$ and $\mathrm{Fe}_{73.5} \mathrm{Cu}_{1} \mathrm{Nb}_{3} \mathrm{Si}_{17.5} \mathrm{~B}_{5}$. Magnetic hardening of the alloys at the onset of crystallization was studied by the two independent techniques, i.e. measurements of the magnetization hysteresis loops and Barkhausen effect. A good correlation between the coercivity and the maximum power of the Barkhausen noise has been found in these two compositions of the alloys.
\end{abstract}

PACS numbers: 75.60.Ej, 75.60.-d

\section{Introduction}

Iron-based metallic glasses are classified as soft magnetic materials. Certain improvement of their magnetic properties can be achieved by annealing treatments, which reduce residual stresses. However, the best soft magnetic behaviour was found in $\mathrm{Fe}-\mathrm{Cu}-\mathrm{Nb}-\mathrm{Si}-\mathrm{B}$ alloys which have a nanocrystalline structure after annealing at sufficiently high temperatures, as reported by Yoshizawa [1]. A transition from the amorphous to nanocrystalline state can be associated with magnetic hardening which manifests itself as an increase in the coercivity [2]. This effect can be ascribed to the magnetoelastic stresses, because both the magnetostriction coefficient and the coercivity exhibit maxima at the same annealing temperature [2]. After annealing at temperatures slightly above crystallization temperature $T_{x}$ (which is about $445^{\circ} \mathrm{C}$ for the $\mathrm{Fe}_{73.5} \mathrm{Cu}_{1} \mathrm{Nb}_{3} \mathrm{Si}_{13.5} \mathrm{~B}_{9}$ and $436^{\circ} \mathrm{C}$ for the $\mathrm{Fe}_{73.5} \mathrm{Cu}_{1} \mathrm{Nb}_{3} \mathrm{Si}_{17.5} \mathrm{~B}_{5}$ alloy) small fractions of the $\alpha-\mathrm{Fe}(\mathrm{Si})$ nanocrystals were observed using $\mathrm{X}$-ray diffractometry [3]. A considerable decrease in the coercive field and the magnetic anisotropy is expected for high fractions of nanocrystals (up to 70\%), as predicted by the theoretical model of Herzer [4]. The Barkhausen 
effect and magnetic hysteresis can be treated as independent methods to study irreversible magnetization processes. The aim of this paper is to compare results of these two magnetic methods in the case of the phase transition from the amorphous to crystalline state.

\section{Results and discussion}

Samples (20 $\mu \mathrm{m}$ thick, $4 \mathrm{~mm}$ wide and $100 \mathrm{~mm}$ long) of the initially amorphous alloys with the following compositions: $\mathrm{Fe}_{73.5} \mathrm{Cu}_{1} \mathrm{Nb}_{3} \mathrm{Si}_{13.5} \mathrm{~B}_{9}$ and $\mathrm{Fe}_{73.5} \mathrm{Cu}_{1} \mathrm{Nb}_{3} \mathrm{Si}_{17.5} \mathrm{~B}_{5}$ were annealed at temperatures ranging from 400 to $560^{\circ} \mathrm{C}$ for a period of 1 hour. A computerized hysteresis loop tracer [5] was used to determine the coercive field $H_{c}$ from the quasi-static magnetization loops. The RMS (root mean square) of the Barkhausen noise signal was measured using a measuring system based on a low-noise amplifier and the RMS to a dc voltage converter. The maximum intensity of the Barkhausen noise was determined from these measurements.

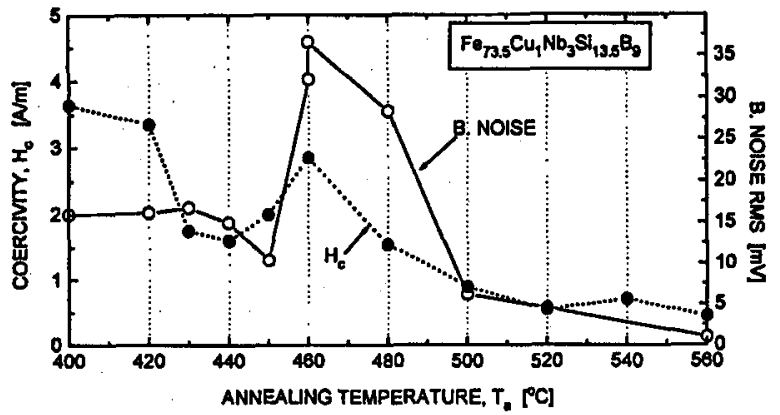

Fig. 1. Influence of annealing temperature on the coercive field $H_{c}$ and the Barkhausen noise of the initially amorphous $\mathrm{Fe}_{73.5} \mathrm{Cu}_{1} \mathrm{Nb}_{3} \mathrm{Si}_{13.5} \mathrm{~B}_{9}$ alloy.

A comparison between the results of the coercivity measurements and Barkhausen effect after isochronal annealing of the $\mathrm{Fe}_{73.5} \mathrm{Cu}_{1} \mathrm{Nb}_{3} \mathrm{Si}_{13.5} \mathrm{~B}_{9}$ alloy at different temperatures is presented in Fig. 1. Both the coercive field and the Barkhausen effect exhibit maxima at the annealing temperature of $460^{\circ} \mathrm{C}$, which is slightly above the crystallization temperature. As a result of the annealing small fractions of the $\alpha-\mathrm{Fe}(\mathrm{Si})$ crystalline grains with diameters below $20 \mathrm{~nm}$ appear in the amorphous matrix. The nanocrystalline grains seem to be too small to be hindrances against domain wall movements. It is more probable that larger defects can be sources of the increased coercivity and the enhanced Barkhausen noise. If the crystallization proceeds inhomogeneously at low crystalline fractions such defects can be produced in the magnetostrictive alloy due to local stresses. It is important to mention that the magnetostriction reaches maximum values for the annealing temperatures close to $460^{\circ} \mathrm{C}$ [2].

A magnetic softening can be observed below the crystallization point, where both the coercivity and Barkhausen noise show minima as functions of the annealing temperature. This behaviour can be explained by structural relaxation of the amorphous alloy which occurs before the crystallization process begins. 


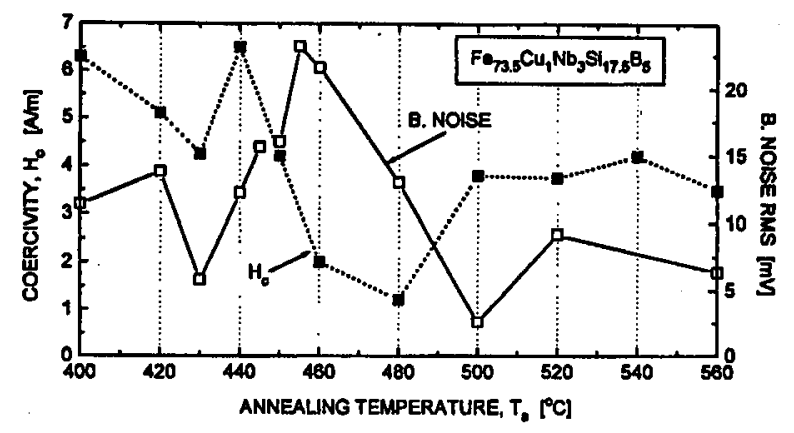

Fig. 2. Influence of annealing temperature on the coercive field $H_{c}$ and the Barkhausen noise of the initially amorphous $\mathrm{Fe}_{73.5} \mathrm{Cu}_{1} \mathrm{Nb}_{3} \mathrm{Si}_{17.5} \mathrm{~B}_{5}$ alloy.

The Barkhausen noise and the coercive field of the $\mathrm{Fe}_{73.5} \mathrm{Cu}_{1} \mathrm{Nb}_{3} \mathrm{Si}_{13.5} \mathrm{~B}_{9}$ alloy decrease monotonously with increasing temperatures of annealing in the temperature range from 460 to $560^{\circ} \mathrm{C}$. The minimum Barkhausen noise intensity in the samples with the maximum crystalline fraction was at least one order of magnitude lower than in the amorphous state. The dependences of the coercive field and the Barkhausen noise intensity in the $\mathrm{Fe}_{73.5} \mathrm{Cu}_{1} \mathrm{Nb}_{3} \mathrm{Si}_{17.5} \mathrm{~B}_{5}$ alloy on the annealing temperature are presented in Fig. 2. The dependences in Figs. 1 and 2 show great similarities, though they differ in details. Again, a magnetic softening preceding crystallization was observed in the annealing temperatures just below crystallization temperature. The maximum of the Barkhausen noise, however, is shifted towards higher temperatures with respect to the maximum of the coercivity. Moreover, instead of a systematic decrease deep minima of the coercivity and the Barkhausen noise were observed at the annealing temperatures higher than $460^{\circ} \mathrm{C}$. The lowest values of these quantities were measured after annealing at temperatures between 480 and $500^{\circ} \mathrm{C}$. Next hardening have been observed for the annealing at temperatures higher than $500^{\circ} \mathrm{C}$. This is the evidence that the crystallization differs in the two compositions of the alloys with different contents of silicon and boron. This fact was confirmed by the X-ray diffractometry. The second softening in the $\mathrm{Fe}_{73.5} \mathrm{Cu}_{1} \mathrm{Nb}_{3} \mathrm{Si}_{17.5} \mathrm{~B}_{5}$ alloy is related to the appearance of the $\mathrm{Fe}_{3} \mathrm{Si}$ crystal grains in the amorphous matrix [2]. This crystalline phase occurs in the $\mathrm{Fe}_{73.5} \mathrm{Cu}_{1} \mathrm{Nb}_{3} \mathrm{Si}_{13.5} \mathrm{~B}_{9}$ alloy after annealing at much higher annealing temperatures, i.e. close to the second stage of crystallization. The second hardening in the $\mathrm{Fe}_{73.5} \mathrm{Cu}_{1} \mathrm{Nb}_{3} \mathrm{Si}_{17.5} \mathrm{~B}_{5}$ nanocrystalline alloy can be associated with precipitations of copper crystals, which do not exist in the $\mathrm{Fe}_{73.5} \mathrm{Cu}_{1} \mathrm{Nb}_{3} \mathrm{Si}_{13.5} \mathrm{~B}_{9}$ nanocrystalline alloy. A certain disagreement (shift) between the dependences of the Barkhausen noise and the coercivity on the annealing temperature in the range from 440 to $520^{\circ} \mathrm{C}$ can arise from the fact that the Barkhausen noise is sensitive mainly to domain wall movements but the coercive field is a result of both domain wall movements and irreversible magnetization rotations.

Both the coercive force and the Barkhausen effect can be successfully used to study structural changes in the alloys. There exists a good correlation between both kinds of measurements. Magnetic hardening (or softening) of the alloy which results from structural relaxation and crystallization of magnetic and non-magnetic 
phases can be detected as peaks (or minima) of the dependences of the coercivity and the Barkhausen noise on the annealing temperature.

\section{Acknowledgments}

A financial support from the Committee for Scientific Research under projects KBN 2P302 07304 and 7T08A 03708 is gratefully acknowledged.

\section{References}

[1] Y. Yoshizawa, S. Oguma, K. Yamauchi, J. Appl. Phys. 64, 6044 (1989).

[2] T. Kulik, A. Hernando, M. Vazquez, J. Magn. Magn. Mater. 133, 310 (1994).

[3] T. Kulik, R. Żuberek, A. Hernando, J. Magn. Magn. Mater. 140-144, 422 (1995).

[4] G. Herzer, IEEE Trans. Magn. 25, 3327 (1989).

[5] T. Kulik, H.T. Savage, A. Hernando, J. Appl. Phys. 73, 6855 (1993). 